\title{
Ultrasonic Phase Array and Eddy Current Methods for Diagnostics of Flaws in Friction Stir Welds
}

\author{
Valery Rubtsov $^{1, \text { a) }}$, Sergey Tarasov
and Sergey Psakhie
(1,2, Ed) \\ ${ }^{1}$ Institute of Strength Physics and Materials Science SB RAS, Tomsk, 634055, Russia \\ ${ }^{2}$ National Research Tomsk Polytechnic University, Tomsk, 634050, Russia

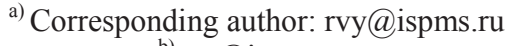 \\ b) tsy@ispms.ru \\ c) eak@ispms.ru \\ d) sp@ispms.ru
}

\begin{abstract}
The feasibility of the defect detection in friction stir welds of aluminum alloys with the use of two different non-destructive testing (NDT) methods has been studied. We have used the following NDT techniques: ultrasonic phase array and eddy current methods. A metallographic examination was chosen as the third method. The weld flaws such as kissing bond boundaries, lack of penetration, voids and cracks have been successfully detected using the ultrasonic phase array technique. The eddy current method enabled the detection of a weld root flaw.
\end{abstract}

Keywords: non-destructive testing, ultrasonic phase array, eddy current, friction stir welding, aluminum alloy

\section{INTRODUCTION}

A great number of publications devoted to friction stir welding (FSW) describe its wide application in the world practice for joining aluminum alloy sheets. A full process description including the description of FSW seam flaws is disclosed elsewhere $[1,2]$.

In connection with the attempts made to use the FSW for manufacturing critical machine parts, including the space structures, more attention was paid to developing the methods for non-destructive testing of the FSW joints.

The objective of this work is to evaluate the applicability of different NDT methods, such as ultrasonic and eddy current techniques, for the aforementioned purpose, and compare them with the results of the destructive metallographic examination.

\section{METHODS}

Wrought AMg5M aluminum alloy sheets with the thickness of $5 \mathrm{~mm}$ were friction stir welded so that the joined samples were $185 \mathrm{~mm}$ in width and had the weld width of $19 \mathrm{~mm}$. The samples were produced using an automatic FSW machine located at the Sespel factory (Cheboksary, Russia) [3]. The FSW process parameters such as plunge force, FSW tool rotation rate and feed rate were varied to obtain the samples containing different types of both open and hidden flaws.

The ultrasonic testing was carried out using a HARFANG VEO 16:128 phase array flaw detector (United Kingdom). The probe wedge was set perpendicular to the weld root side and $11 \mathrm{~mm}$ away from the centerline. During the weld scanning, a normal force of $10 \mathrm{~N}$ was applied to the wedge that was driven along the seam at the velocity of about $2 \mathrm{~mm} / \mathrm{s}$ using a system of electric drives. The sector S-scans of the cross sections of butt welds were obtained and recorded with $0.2 \mathrm{~mm}$ step, and then a full ultrasonic (US) defect image of the weld joint was reconstructed.

International Conference on Physical Mesomechanics of Multilevel Systems 2014

AIP Conf. Proc. 1623, 539-542 (2014); doi: 10.1063/1.4899001

(C) 2014 AIP Publishing LLC 978-0-7354-1260-6/ $\$ 30.00$ 


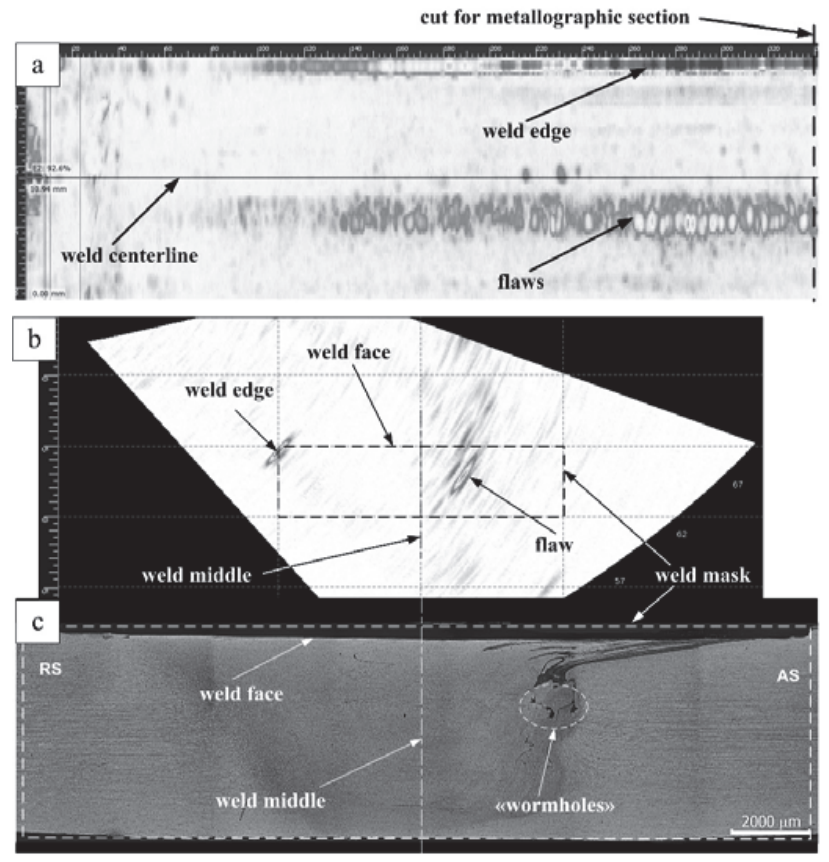

FIGURE 1. "Wormhole" weld defects: (a) US "top-view", (b) US S-scan, and (c) metallographic section

To enable the eddy current testing we have used an Ectane ${ }^{\mathrm{TM}}$ portable flaw detector (South Africa) operated at $4 \mathrm{~V}, 50 \mathrm{~Hz}$. The eddy current probe comprised 30 coils and had the working part with the width of $50 \mathrm{~mm}$. The probe was set perpendicular to the weld root side with their centerlines coincided. A normal force of $10 \mathrm{~N}$ was applied to the probe that was driven along the weld at the velocity of $10 \mathrm{~mm} / \mathrm{s}$. The scans were obtained and recorded with the step of about $0.1 \mathrm{~mm}$ step. Then both axial and transversal scans were reconstructed for the entire weld.

For the purpose of confirming the NDT results and revealing type, location and size of the defects, we examined the cross section polished views of the samples using an optical microscope.

\section{RESULTS AND DISCUSSION}

The US image of defects shown in Fig. 1 can be considered as a transparent plain view of the entire sample where all the defects can be seen independently of their depth below the surface. One can see that all defects have the form of chain-like band at the same depth and at the distance of 2-3 $\mathrm{mm}$ from the weld centerline closer to its advancing side (AS).

For identifying the defects, we prepared the cross section polished view of this weld in the plane as shown by the dashed line in Fig. 1(a). Comparing the US-scan image of the defect in Fig. 1(b) and the optical cross section image in Fig. 1(c) one can see that the location of the US-scan defect zone in Fig. 1(b) coincides with that of voids in the optical cross section view (Fig. 1(c)).

The almost equiaxed voids are located in the AS at depth from 1 to $2.5 \mathrm{~mm}$ below the weld surface and can be denoted as "wormhole" defects according to the common classification. The size of this zone may vary, but its right boundary will be always at the interface of the weld and base metal. Generation of that type of defect is related to the specificity of friction-plasticized and modified metal flow in the vicinity of a stationary base metal [4].

One of the samples was prepared for welding by drilling five equally spaced holes in it with the diameter of $5 \mathrm{~mm}$ and the depth of $3 \mathrm{~mm}$. After the welding there were 5 visible lack of penetration defects. Moreover, the USimaging showed the presence of numerous internal hidden defects (Fig. 2(a)). The relevant zone containing the hidden defects was studied by the preparation and the metallographic examination of its cross-section view. 


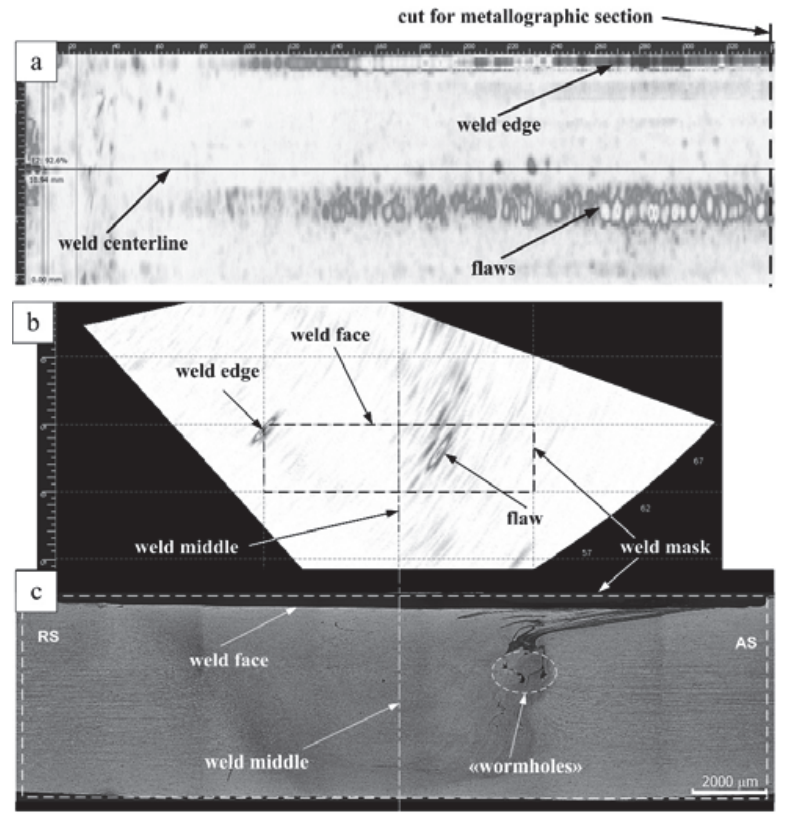

FIGURE 2. Lack of penetration internal weld defects: (a) US "top-view", (b) US S-scan, and (c) metallographic section

The US-scan and the weld cross-section view are shown in Fig. 2(b, c), respectively. It should be noted that the US-image demonstrates not the entire sample, but only a $1.5 \mathrm{~mm}$ layer close to the weld face as shown in Fig. 2(b). Again, we can observe the coincidence of the location of the defect-containing zone in the S-scan (Fig. 2(b)) and the real location of the defect in the cross section view (Fig. 2(c)).

Examination of the cross section view reveals a subsurface with the width of 2-3 $\mathrm{mm}$ and the depth of $2 \mathrm{~mm}$ having the lack of penetration defect along the weld centerline (Fig. 2(c)). This defect is a cluster of voids with various sizes and shapes and having the asymmetrical shape with respect to the weld centerline.

This type of defect is the lack of penetration itself that was smoothed by the FSW tool shoulder. The inner structure of the defect reminds that of rocks. The similar structure is also observed inside of the open type defects. Although this type of defects can be found in the vicinity of the weld surface with the minimum location depth of about $100 \mu \mathrm{m}$ (Fig. 2(c)), it cannot be detected by visual inspection.

Another interesting fact, which has to be elucidated, is that the defect occurrence in the US-image coincides with the weld seam edge (Fig. 1(a) and Fig. 2(a)).

Moreover, the friction stir weld joints were subjected to the non-destructive testing after removing a layer of metal by milling, the residual thickness being equal to $2.5 \mathrm{~mm}$. The US testing enabled detecting a discontinuity defect with the length comparable to that of the weld in the vicinity of the weld root side. This defect was also detected using the eddy current testing as shown in Fig. 3. Comparing the results obtained using both the US (Fig. 3(a)) and eddy current (Fig. 3(b)) methods demonstrates that the consistency between detection of defects is observed only for the certain segments of the weld.

For some segments more defects were found by the US technique, while some of them were found by the eddy current method. The eddy current testing was unable to detect a chain-like defect 2-3 $\mathrm{mm}$ away from the weld centerline, which was clearly visible in the US-image (Fig. 3(a)). The cross section plane for metallography was chosen to enable visualization of both the root flaw and one of the chain-like defects parallel to the weld centerline.

The defect location in the US S-scan (Fig. 3(c)) coincides again with that of the real defects shown in the cross section view (Fig. 3(d)). The defect in Fig. 3c located closely to the weld centerline is a reflection from a crack developed along the "Lazy S" line. Another defect corresponds to the shorter crack located on the advancing side.

It should be noted that the aluminum alloy sheet edges were not mechanically processed to remove the oxides and, therefore, the Lazy S defects were present in all samples; however, they were detected only when a crack propagated along it. 

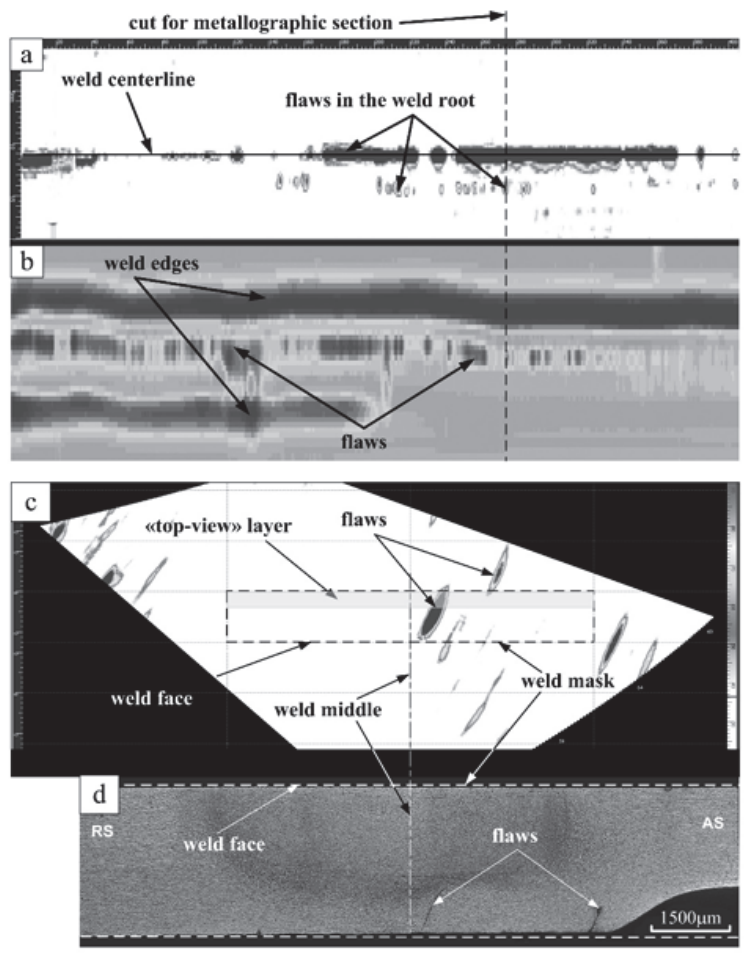

FIGURE 3. Lack of penetration internal weld defects: (a) US “top-view”, (b) eddy current scan, (c) US S-scan, and (d) metallographic section

\section{SUMMARY}

Apart from the Lazy S defect, the US phase array testing allowed detecting almost all other types of defects such as $200 \mu \mathrm{m}$ voids and small opening cracks.

The eddy current testing allowed detecting only crack-like defects open to the surface. The crack-like defect along the weld root detected by the eddy current method did not coincide with that found in the US image. Taking into account potentially high sensitivity of the method, we consider the non-optimal instrument calibration and scanning parameters to be the possible reasons of such phenomenon.

\section{ACKNOWLEDGEMENT}

The work was supported by the Ministry of Education and Science of the RF (Contract No. 02.G25.31.0063) in the framework of the RF Government Decree No. 218.

\section{REFERENCES}

1. R. S. Mishra and M. Mahoney, Friction Stir Welding and Processing (ASM International, 2007).

2. D. Lohwasser and Zh. Chen (Eds.), Friction Stir Welding: From Basics to Applications (Woodhead Publishing Limited and CRC Press LLC, 2010).

3. V. A. Bakshaev and P. A. Vasilyev, Non-Ferrous Metals 1, 75 (2014).

4. V. E. Rubtsov, S. Yu. Tarasov, and A. V. Kolubaev, Phys. Mesomech. 15(5-6), 337 (2012). 